\title{
Volume of Institutional Credit and Land holding Size of Farmers in India
}

\author{
Sarbani Sarkar
}

Department of Economics, Ranaghat College, Nadia, West Bengal, India

Corresponding author: sarbanisarkar79@rediffmail.com (ORCID ID: 0000-0001-6774-9719)

Received: $12-04-2020$

Revised: $18-07-2020$

Accepted: $22-08-2020$

\begin{abstract}
Institutional credit is one important input for progressive agriculture. We expect efficient role of land to generate formal credit for the small farmers in the post tenancy reform period in India as secured land holding is ensured by such land reform policy. We have used NSSO $70^{\text {th }}$ round unit level data on survey of agricultural households and quantile regression as a method to support the paper empirically. Volume of institutional credit is our dependent variable which is explained by land holding as well as different household level characteristics like caste, gender, religion and education. We found formal schooling, land and caste as significant factors to control the volume of formal credit but at different extent for different quantile ranges of the formal credit in India. Up to fiftieth quantile of institutional credit, land is more helpful to those who borrow more. But one unit of land is rather less helpful in generating higher volumes of credit in the quantile ranges above the median level. We conclude redistribution of land is essential to increase financial inclusion in India.

Highlights

0 Land redistribution through reform measures helps small and marginal farmers in arranging institutional loan more than the large cultivators.
\end{abstract}

Keywords: Institutional, credit, volume, land, farmers

Asset holding is essential for borrowing from institutional sources (Jodha 1971; Rao 2007; Dev 2006). Land held by the rural cultivators of India is the only form of asset for majority of them. Hence it can largely determine the volume of credit sanctioned from the formal credit suppliers for the farming community of the country. We may conventionally justify the idea that a large size of land generally supports large volume of formal credit and vice-versa. But that will restrict us to judge contribution of land quantitatively. In other words, it suggests that without increasing the size of holding we cannot raise the amount borrowed from formal sources. In contradiction to the above proposition we can argue that institutional indebtedness may improve instead of holding small size of land by the farmers. We expect qualitative change in the life of cultivator may happen even if the land holding changes by small quantity. As a result an indirect effect may be generated by land to make farmers prone to decide to arrange loan from institutional sources (Bagchi 1998). In other words, small farmers, who can get only small volume of credit, may be benefited more by one extra unit of land than other large size cultivators in terms of marginal contribution of land in arranging loan from formal sources. Such indirect effects may be due to a feeling of more secured about the right on the share of produce or by the nature of the tenancy right itself. For example, in West Bengal a 'Bargadar' has the

How to cite this article: Sarkar, S. (2020). Volume of Institutional Credit and Land holding Size of Farmers in India. Economic Affairs, 65(3): 421-425.

Source of Support: None; Conflict of Interest: None 
right to apply for loan from the institutional sources. Further the current credit policy has included the farmers of the country in such a way that small and marginal farmers may get formal credit with greater accessibility.

Secondly, the conventional idea also suggests that volumes of formal credit will rise with increase in land size which contradicts with reality. In fact average amount borrowed from formal sources may be of small volume even if the size of holding is quite high. Kinship or relatives may affect the decision making to a significant extent. As such formal borrowing may be affected due to different other factors except land holding size (Sen et al. and Dreeze 1997; Deb et al. 1997). Some of them are household specific as well as qualitative. It is therefore more important to find out how land is generating credit than how much credit is generated by land.

However, empirical evidence regarding the issue is rare considering the whole country. But several individual research works have been done at either any particular state level, or at district level. We must mention some of them. Radhakrishan et al. (1988) found a negative correlation between the credit disbursed to the small and marginal farmers and size of holding in Kerala. Co-operatives were the main source of credit as they considered. Similar view was supported by Bhatia (1975) but he also found the credit sanctioned per farm was higher for the large size land holdings. In contradiction to the above view, Rath (1989) argued more long term loans were borrowed by the medium and semi-medium size farmers and marginal farmers have borrowed from institutional sources for short term only. However neither of the above papers has considered marginal contribution of land for different ranges of credit.

We thus try to judge the efficiency of the land and other controlling factors by finding out which volume of credit is more benefited in the present economic frame work of the country. Accordingly our objective is to study the incidence of indebtedness of the farmers considering land as the most important determining factor behind the volume of credit. Nevertheless the other factors also play important role in our analysis, among which most are household level characteristics.
Lower quantiles of formal outstanding credit usually represent the majority of marginal and small farmers. We want to find out how the predictor variables play different role for different quantiles of institutional indebtedness. As such we want to test the following hypotheses.

1. Land contributes positively more for the lower volumes of credit than.

2. For any other caste than general caste formal borrowing reduces more in lower quantiles of formal credit.

3. Education has a positive impact on formal credit for all quantiles. We expect a literate farmer has higher institutional indebtedness than who is illiterate and the rate of change is higher for higher volumes of credit.

4. Volume of formal credit reduces by lower amount for higher quantiles if the cultivator is a male than a female.

5. Being a follower of Islam religion, a cultivator has lower formal credit compared to any other religion.

\section{MATERIALS AND METHODS}

We shall use unit level data collected by National Sample Survey Office on $70^{\text {th }}$ round as Key Indicators of Situation of Agricultural Households in India. This round of NSSO specifically collected information from the agricultural households ${ }^{1}$ for the two agricultural seasons under two visits ${ }^{2}$ to the same household. January to August of the year 2003 was the Kharif season and September to December was chosen as the Rabi season of the year. While collecting information, this round has covered land and livestock, debt and investment and situation assessment of farmers in the country. To avoid errors in the estimation, stratification at different levels of data collection has been done following the rule of proportion of population for different states. We have extracted relevant portion of data from the situation assessment part of the unit level data.

Ordinary least square can only predict change in the average institutional debt due to change in the

\footnotetext{
${ }^{1}$ An agricultural household is defined as a household receiving some value of produce from agriculture and if at least one member of the family is self-employed either in principal or subsidiary status and earns at least Rs 3000 during the last 365 days. See' Concepts and Definitions, NSSO $70^{\text {th }}$ round, pg. B-1 for detail on the issue.

${ }^{2}$ However in $2^{\text {nd }}$ visit, information on land possessed, food, awareness of minimum support price were not collected.
} 
land by one unit. We are interested in the average changes for different volumes of credit. Hence we have followed here quantile regression method originally developed by Koenker and Bassette in 1978. This method is popularly discussed as median regression analysis in the literature of econometrics. There are two important reasons of choosing this method here, firstly, the method do not responds to outliers existing in the model and secondly it does not assume the constant variance of the error term. For the first we can avoid over or under estimation of the coefficients of the explanatory variables, for the later heteroscedasticity of the error variance is allowed in the model. The mathematical interpretation does not differ much from the general exposition of OLS but the difference is, we find conditional mean under the OLS and estimate median as well as different percentiles under quantile regression. Such estimation process has some positive points as estimation of mean may over or under estimate some of the percentiles which restrict us to differentiate between the impacts of the independent variables over different ranges of the dependent variable. The following is the general form of the equation of the model:

$$
y_{i}=x_{i}^{\prime} \beta(\tau)+u_{i}(\tau)
$$

Here $y_{i}$ is the total outstanding debt of the farmers (log values) and $x_{i}$ is a $(\mathrm{k} \times 1)$ vector of the explanatory variables. The corresponding coefficients vector is represented by $\beta$, and $(\tau)$ refers to the percentile we are interested to estimate. Here can take any value between 0 and 1 . The value of the coefficients vary across different percentiles is the underlying assumption. $Q_{t}($.) represents the quantile function, which is also the inverse function of $F($.$) , where$ $F($.) refers to the cumulative distributional function of $y_{i}$ as $y_{i}$ is the conditional function of $x_{i}$. Then the quantile function can be represented as,

$$
Q_{\tau}\left(y_{i} / x_{i}\right)=x_{i}^{\prime} \beta(\tau) \ldots
$$

$u_{i}(\tau)$ denotes the error term which for the $\tau^{\text {th }}$ quantile follows,

$$
Q_{\tau}\left(u_{i}(\tau) \mid x_{i}\right)=0
$$

Then the parameters are estimated for the $\tau^{\text {th }}$ quantile by minimizing the weighted absolute deviations, which can be represented as follows:

$$
{ }_{\beta \in R^{k}}^{\operatorname{Min}}\left[\sum_{i \in\left\{i: y_{i}<x_{i} \beta\right\}} \tau\left|y_{i}-x_{i} \beta\right|+\sum_{i \in\left\{i: y_{i} \geq x_{i} \beta\right\}}(1-\tau)\left|y_{i}-x_{i} \beta\right|\right] \ldots
$$

Outstanding institutional debt of the farmers is our dependent variable and total land possessed, is considered as the independent variable with other explanatory variables like caste, gender, religion, education. The first two are quantitative variables and we have considered the log values of them in our analysis. Remaining variables are the qualitative variables and we have created dummies for them. The original data has information on the total outstanding credit to the institutional sources like Government, Banks and co-operatives. We have first extracted the data regarding credit amount corresponding to these sources and used for our analysis. Keeping the general caste of the farmers as the base group we have generated the dummy variable for the scheduled caste, scheduled tribe and other backward class. Gender dummy is generated to compare the male farmers with the female farmers as the latter group is more prone to have informal credit indebtedness. Farmers having formal schooling are compared to those farmers who are illiterate. The religion dummy is generated keeping the Hinduism and other religions as the base group.

\section{RESULTS AND DISCUSSION}

We have shown the empirical result in the following table. The table shows the regression result for different quantiles as well as the regression result for the coefficients under ordinary least square.

However, the coefficients of the OLS help us to get the change in the dependent variable due to one unit change in the predictor variable on average. The first column shows all the explanatory variables are significant at one percent level except religion which is significant at five percent level. The next seven columns are showing the coefficients of quantile regression for fifth, tenth, twenty-fifth, fiftieth, seventy-fifth, ninetieth and ninety-fifth quantile of the distribution of institutional outstanding credit among the farmers in India.

First we shall explain the simple coefficients of OLS. The constant term (intercept) indicates the 
Table 3: Quantile regression result for different quantiles

\begin{tabular}{|c|c|c|c|c|c|c|c|c|}
\hline Log institutional credit & OLS coefficients & Q5 & Q10 & Q25 & Q50 & Q75 & Q90 & Q95 \\
\hline Constant & $10.60^{* * * *}$ & $8.89^{* * *+}$ & $9.29^{* * *+}$ & $9.84^{* * *}$ & $10.59^{* * *}$ & $11.29^{* * *}$ & $12.00^{* * * *}$ & $12.35^{* * *}$ \\
\hline Log land & $0.32^{* * * *}$ & $0.35^{* * *}$ & $0.35^{* * *}$ & $0.39^{*+*+}$ & $0.37^{* * * *}$ & $0.30^{* * *}$ & $0.25^{* * *}$ & $0.25^{* * *}$ \\
\hline D_st & $-0.69^{* * *}$ & $-0.95^{* * *}$ & $-0.74^{* * *}$ & $-0.56^{* * *}$ & $-0.65^{* * *}$ & $-0.74^{* * * *}$ & $-0.61^{* * * *}$ & $-0.52^{* * *}$ \\
\hline D_sc & $-0.37^{* * *}$ & $-0.28^{* *}$ & $-0.18^{* * *}$ & $-0.21^{* * *}$ & $-0.28^{* * *}$ & $-0.49^{* * * *}$ & $-0.69^{* * * *}$ & $-0.32^{* *}$ \\
\hline D_obc & $-0.13^{* * *}$ & -0.14 & 0.04 & 0.03 & $-0.15^{* * *}$ & $-0.30^{* * *}$ & $-0.14^{* * *}$ & 0.00 \\
\hline Formal schooling & $0.232^{* * *}$ & 0.04 & $0.08^{*}$ & $0.13^{* *+t}$ & $0.26^{* * *}$ & $0.33^{* * *}$ & $0.30^{* * *}$ & $0.36^{* * *}$ \\
\hline D-gender & $-0.06^{* *}$ & -0.11 & $-0.19^{* * *}$ & -0.03 & $-0.07^{* *}$ & -0.04 & -0.02 & -0.03 \\
\hline Religion & $-0.13^{* * *}$ & -0.10 & $-0.18^{* * * *}$ & -0.05 & 0.01 & 0.01 & -0.09 & -0.17 \\
\hline
\end{tabular}

Note: ${ }^{* *+}$ implies significant at 1 percent level, "*indicates significance at 5 percent level and "shows significance at 10 percent level. The rest of the values of the above table are insignificant.

Source: Author's calculation using unit level data from NSSO $70^{\text {th }}$ round.

average amount of formal credit that a cultivator holds when all the other independent variables are theoretically equal with zero. In other words this amount of institutional credit is not affected by any factors among the farmers who are indebted or it may be called the minimum level of loan needed for an agricultural household. Coefficient of land indicates one additional unit of land holding increases the institutional credit by rupees 0.32 . Next the coefficients of the caste dummies are interpreted in reference to the formal credit in hand of the farmers of general caste. For example, we find the formal credit decrease by rupees 0.69 for a farmer being scheduled tribe caste instead of being general caste. Similarly we find negative significant coefficients for the other castes also which indicates a cultivator of general caste may better access over institutional credit than any other caste in the country. Compared to an illiterate farmer rupees 0.23 more credit is arranged from formal source by a cultivator who has formal schooling. Interestingly a male farmer has less indebtedness from formal source than a female cultivator and the result is significant at 5 percent level. A farmer of Islam community is involved with less formal borrowing than farmers of any other community. Interestingly such difference of institutional borrowing across religion is significant at 1 percent level.

After considering the OLS results now we compare the coefficients for different quantiles with the OLS coefficients and to better interpret the pattern of distribution of institutional indebtedness. For all the quantiles, the constant term is positive and significant at 1 percent level. For higher volumes of institutional credit, the constant term is higher. Apparently this can be explained as large farmers have increased amount of autonomous credit from institutional sources for investment in agriculture.

Land as an explanatory factor is more helpful for the higher quantiles as we consider the coefficients starting from the fifth quantile and move towards the fiftieth quantile. It is thus clear that one additional unit of land increases the institutional credit at an increasing rate as the volume of formal credit increases up to the median level. Beyond the median volume of credit land contributes less in formal credit arrangement. Further we find the simple OLS coefficient of land underestimates the coefficients of the first four quantiles. In reality land is more helpful on average than what a simple regression suggests to us to generate small volumes of credit. But we do not find higher coefficient for the fifth or tenth quantile than what we find for the median regression. However a reduced coefficient of land for such large volumes of loan shows that there are other important factors to influence the institutional credit than land.

Scheduled tribe farmers, belonging to all quantiles of formal credit distribution have reduced indebtedness compared to the farmers of general caste at 1 percent level of significance. Such negative responsiveness is underestimated for the fifth, tenth and seventy-fifth quantile by the mean estimation. The coefficient is highest for the fifth quantile. In other words, the institutional borrowing reduces by highest rate in the first fifth quantile of total formal loan for a scheduled tribe farmer than a general caste cultivator. It also refers to caste is important determinant of the institutional indebtedness for the small and marginal farmers more than the large land holders in the country. 
Formal schooling has significant positive effect to increase the institutional credit in all the quantile ranges except the fifth quantile. We may interpret it as a farmer being formally educated borrows more from formal sources than a cultivator who is illiterate if their volume of credit is high. It is important that though the coefficient is not significant for the fifth quantile but the sign of the coefficient is positive. Again OLS estimation underestimates the effect of formal education on the incidence of indebtedness to the formal sector for the farmers who are able to borrow large volumes of credit.

We find the coefficients of gender dummy gradually decreases for the higher quantiles indicating a farmer being male has lower volume of formal borrowing rather than a female cultivator and the extent of difference reduces for large volumes of credit. Though we did not find significant result for each quantile of institutional indebtedness but interestingly the fifth and tenth quantile have lower negative coefficients than that we estimated under OLS. Thus male cultivators are more indebted with informal borrowing than their female participants in the lower quantile ranges of credit.

Religion has almost insignificant impact on the volume of institutional indebtedness for every range of institutional credit except in the tenth quantile. But we found negative values in most of the quantiles. It indicates lower institutional debt for a cultivator of Islam community than Hindu and others.

\section{CONCLUSION}

The land holding size is an important determining factor of the volume of institutional credit borrowed by cultivators in India. In fact land is more rewarding to get institutional credit for marginal cultivators. We find caste is still a sensitive issue for the rural agricultural section. The volume of institutional credit is generally lower for the farmers of reserved category compared to the general caste farmers for any quantile rage of formal loan. The extent of such difference is different for scheduled caste and scheduled tribe farmers. Wider access over primary education will lead to institutionalisation of the farmers as we found positive contribution of literacy on formal loan. We also conclude institutional loan is less accessed by men farmers than women following the study. As such only redistribution of land to the poor farmers will not be sufficient to increase the institutionalization of credit. Rather such land policy measure has to be supported by other policy measures to reduce inter caste and inter gender differences and more effective spread of education among the village cultivators.

\section{REFERENCES}

Bagchi, A.K. 1998. Studies on the Economy of West Bengal Since Independence. Economic and Political Weekly, 33(47/48): 2973-2978.

Bhatia, J.P. 1975. Problems of Small Farming- A Case study of Tribals.(U.P). Indian Journal of Agricultural Economics, 30(3): 240.

Deb, S. and Rajeev, M. 2007. Banking on Baniyas for Credit. Economic and Political Weekly, 42(4): 280-283.

Dev, S.M. 2006. Financial Inclusion: Issues and Challenges. Economic and Political Weekly, 41(41): 4310-4313.

Jodha, N.S. 1971. Land- Based Credit Policies and Investment Prospects for Small Farmers. Economic and Political Weekly, 6: 145-148.

Koenker, Roger and Hallok, K.F. 2001. Quantile Regression. The Journal of Economic Perspectives, 15(4): 143-156.

Mukund and Radhakrishan. 1988. Supply and Utilization of short term co-operative agricultural credit in Phalaghat District of Kerala. Indian Journal of Agricultural Economics, 43(3): 429.

Rao. K.G.K.S. 2007. Financial Inclusion: An Introspection. Economic and Political Weekly, 42(5): 355-360.

Rath, N. 1989. Institutional Credit for Agriculture in India. Journal of Indian School of Political Economy, 1(2): 239-267.

Sarap. Kailas. 1991. Collateral and other Forms of Gurantee in Rural Credit Markets: Evidence from Eastern India. Indian Economic Review, New Series, 26(2): 167-188. 
